\title{
Review
}

\section{Vanadium catalyzed oxidation with hydrogen peroxide}

\author{
Valeria Conte*, Barbara Floris \\ Dipartimento di Scienze e Tecnologie Chimiche, Università di Roma Tor Vergata, Via della Ricerca Scientifica, 00133 Roma IT, Italy
}

\section{A R T I C L E I N F O}

\section{Article history:}

Received 15 April 2009

Received in revised form 18 June 2009

Accepted 29 June 2009

Available online 8 July 2009

\section{Keywords:}

Vanadium

Oxidation

Hydrogen peroxide

Mechanisms

Ionic liquids

\begin{abstract}
A B S T R A C T
Vanadium peroxides are known as very effective oxidants of different organic and inorganic substrates. In this short account reactivity, structural and mechanistic studies concerning the behaviour of peroxovanadates toward a number of different substrates are collected. Homogeneous and two-phase systems are presented, in addition, interesting synthetic results obtained with the use of ionic liquids as reaction media are also presented.
\end{abstract}

(ㄷ) 2009 Elsevier B.V. All rights reserved.

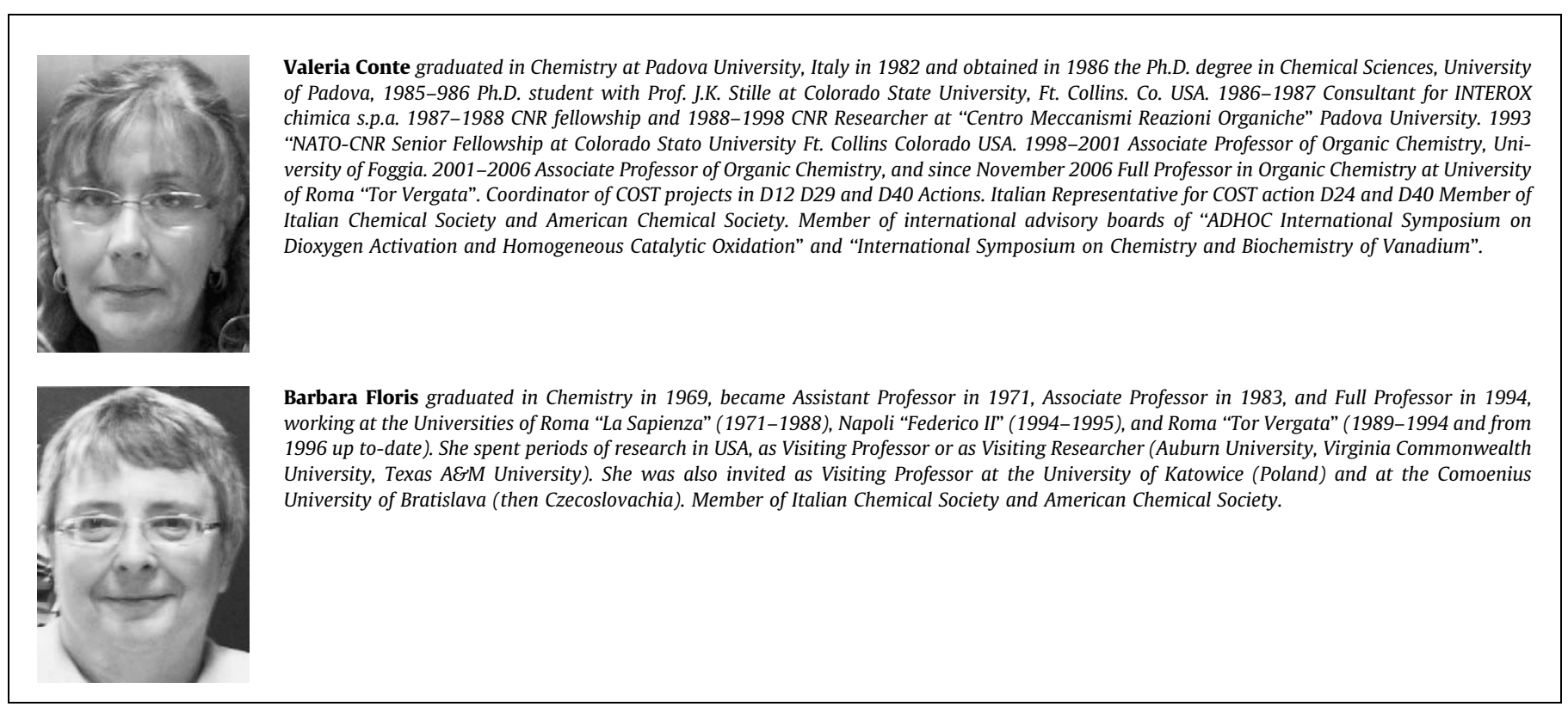

\footnotetext{
* Corresponding author.

E-mail address: valeria.conte@uniroma2.it (V. Conte).
} 


\section{Contents}

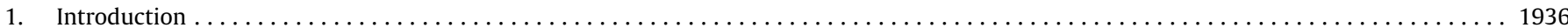

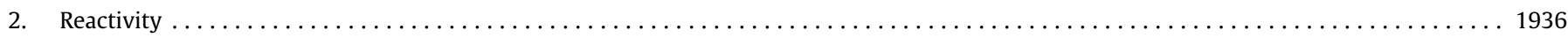

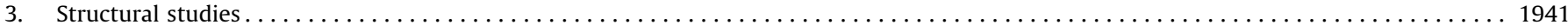

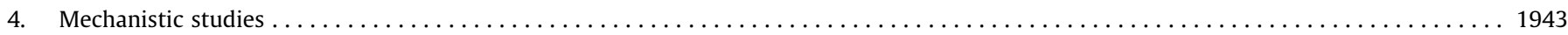

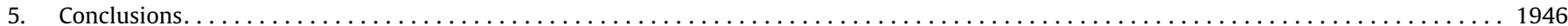

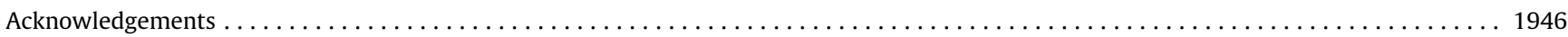

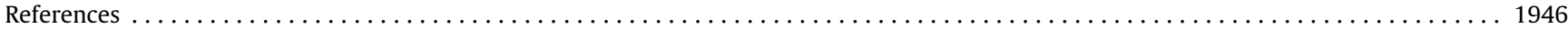

\section{Introduction}

Among transition metals, vanadium is the second most abundant in the sea water (ca. $30 \mathrm{nM}$ mainly in the soluble form of $\mathrm{NaH}_{2} \mathrm{VO}_{4}$ ). Vanadium is also present in soils and fresh water both as vanadate, $\mathrm{V}(\mathrm{V})$, and vanadyl, oxido-V(IV) [1]. This metal is therefore available for living organisms, in particular in marine environment. In fact quite a few enzymes containing vanadium in the active site are known. Between them, vanadate dependent haloperoxidases enzymes, isolated from red and brown algae, catalyze the oxidation of halide ions by hydrogen peroxide [2] and are known to play a major role particularly in the biosynthesis of brominated compounds. The catalytic effect is related to the formation, in the active site, of the enzyme of a peroxido vanadium species which is a much stronger oxidant in comparison with $\mathrm{H}_{2} \mathrm{O}_{2}$. These peroxido derivatives oxidize the bromide ion to form a brominating intermediate which then either brominates the organic substrate or reacts with another bromide ion.

More related to the classical catalytic oxidation reactions is the knowledge that vanadium peroxides are very effective oxidants of different organic and inorganic substrates like sulfides, alkenes, alcohols, aromatic and aliphatic hydrocarbons, halides and sulfur dioxide, as summarized in Scheme 1 [3].

These reactions either stoichiometric or catalytic, where the terminal oxidant is normally hydrogen peroxide or an alkylhydroperoxide, are carried out, on average, in mild conditions and associated to good product yield and selectivity. The enantioselective version of some of these processes has been also reported [3].

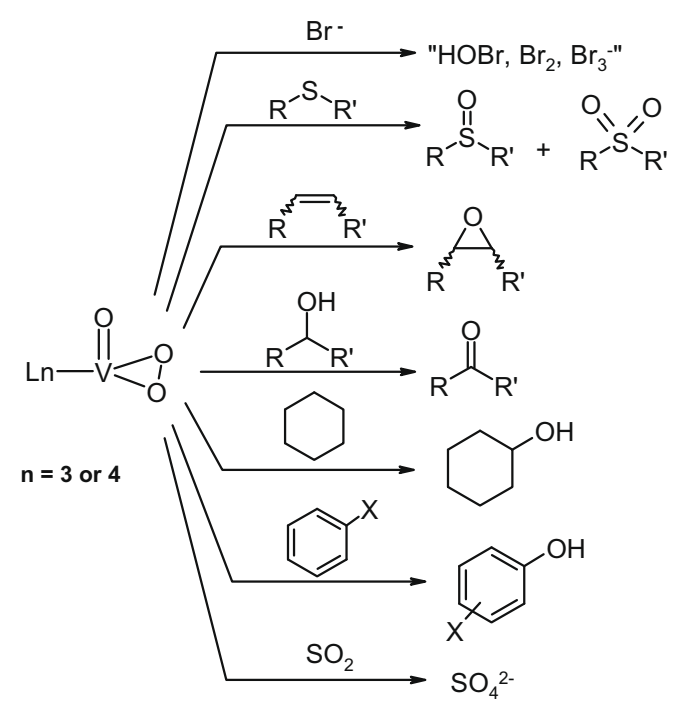

Scheme 1. Typical oxidation reactions carried out in the presence of vanadium side-on peroxides complexes. L can be an organic ligand or a solvent molecule. Stoichiometric, with isolated species, and catalytic, with $\mathrm{H}_{2} \mathrm{O}_{2}$ as terminal oxidant, processes are known [3].
Vanadium and vanadium peroxides, in addition, generate a number of biological and biochemical responses [1,4] and retain a potential as insulin-enhancing agents in the treatment of human diabetes of type 2 [1,5].

The number and the nature of peroxidovanadates formed upon addition of hydrogen peroxide to vanadium precursors depend on $\mathrm{pH}$, added ligands and relative concentrations of the reagents. Quite recently we showed that the association of electrospray ionization mass spectrometry (ESI-MS) with ${ }^{51} \mathrm{~V}$ NMR spectroscopy and theoretical calculations can be a valuable tool to obtain a detailed speciation of the $\mathrm{V}(\mathrm{V})-\mathrm{H}_{2} \mathrm{O}_{2}-\mathrm{H}^{+}$-ligand systems [6,7]. The identification of the vanadium complexes, for a particular experimental condition, is clearly fundamental in order to understand the mechanisms and products distribution of reactions in which such species are involved.

All our work carried out in the field of solution characterization of vanadates and peroxidovanadates is assembled, in a concise form, in rather recent reviews [7,8] and interested readers are thus referred there or to the original papers [6,9-12], nevertheless, some of the main figures in the field will be presented here.

In this short account, dedicated to our involvement in the application of vanadium catalysis in organic synthesis, we mainly illustrate the peculiar oxidative performance of various V-peroxido derivatives toward alkenes, alkynes and aromatics. In addition to the classical epoxidation or hydroxylation reactions, we also call attention to oxybromination of double and triple bond. On top, we put on view our, very interesting and more recent, results achieved by using ionic liquids as new solvents, in place of the classical chlorinated molecular ones. This aspect attracted our concern, in order to meet with our systems one of the stringent modern requirements of "Green Chemistry" [13], i.e. the reduction of the amount of volatile organic compounds (VOCs) in synthetic innovative procedures.

Finally, some of the mechanistic details of the reactions studied will be shortly reviewed.

\section{Reactivity}

The mode of action of $\mathrm{V}$-dependent bromoperoxidases enzymes (V-BrPO) have stimulated several research groups in searching for an effective functional model for their reactivity $[1,4,14]$. Our contribution in the field dates back to the early 90s of the last century, when, inspired by the mode of action of such enzymes see Scheme 2, we developed a synthetic procedure for the bromination of organic substrates in a two-phase system $\left(\mathrm{H}_{2} \mathrm{O} / \mathrm{CHCl}_{3}\right)$ (Scheme 3).

Our proposal derived from the knowledge that the accepted mode of action of V-BrPOs [4] involves the presence of vanadium in their active sites; this metal in the presence of hydrogen peroxide forms a peroxido vanadium derivatives which oxidizes a bromide ion, thus forming a bromine equivalent intermediate. Such an intermediate may then either brominate an appropriate organic substrate or react with another molecule of terminal oxidant thus 


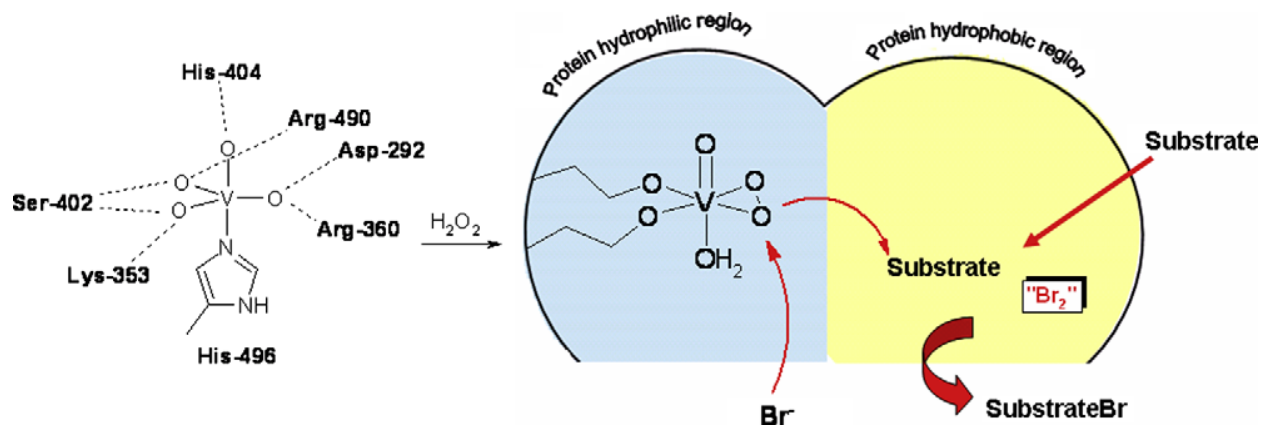

Scheme 2. Simplified description of the mode of action of $V(V)$ dependent haloperoxidases enzymes $[2,4,15]$.

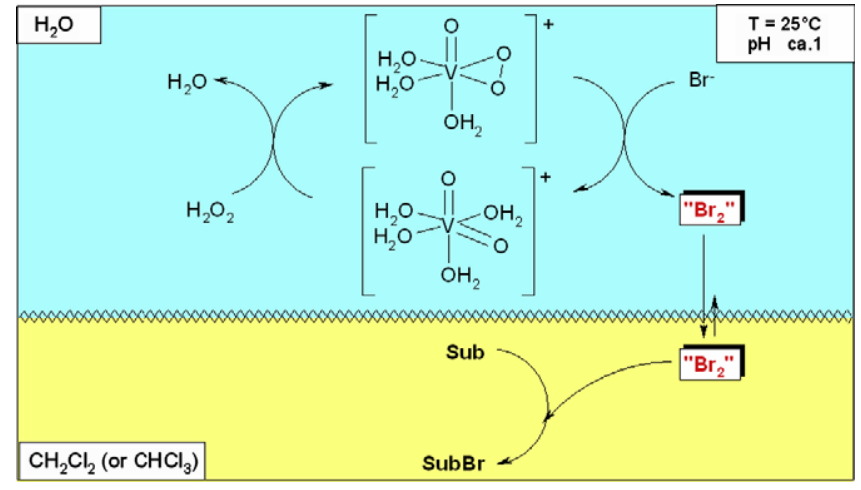

Scheme 3. $V(V)$ based two-phase system for bromination reactions [16].

causing the decomposition reaction. In spite of the fact that the two reactions occurs concurrently, the chemoselectivity of the enzyme catalyzed reactions is very high and thus the yields of brominated products, based on the $\mathrm{H}_{2} \mathrm{O}_{2}$ consumed is also very high. This evidence suggests that the formation of the intermediate and the bromination reaction occur in two different compartments of the enzymes. In particular the former process should take place into a hydrophilic portion present nearby the active site of the enzyme, whereas the latter reaction should take place into a hydrophobic region.

Following this line of reasoning, we have developed a biphasic procedure (see Scheme 3 ) where a vanadium precursor, $\mathrm{H}_{2} \mathrm{O}_{2}$ and $\mathrm{KBr}$ are dissolved in water. In such catalytic phase the formation of a peroxido vanadium derivative and the oxidation of $\mathrm{Br}^{-}$take place. The intermediate thus formed is then transferred into the organic phase, generally a chlorinated solvent i.e. $\mathrm{CHCl}_{3}$ or $\mathrm{CH}_{2} \mathrm{Cl}_{2}$, where the functionalization of the substrate occurs [16,17]. To note, the process in the aqueous phase requires acid conditions, likely to permit protonation of the peroxido moiety. Direct evidence on the formation of a hydroperoxido intermediate, however, have not been obtained.

The results obtained with model aromatic substrates are collated in Table 1. Interestingly, from the synthetic point of view, even more attractive results were obtained by using Mo-catalysis.

First of all, a clean and cheap oxidant, $\mathrm{H}_{2} \mathrm{O}_{2}$, and a sustainable source of positive bromine, such as $\mathrm{KBr}$, are used in very mild conditions. Moreover the products are easily isolated from the reaction mixture. In fact they are obtained almost pure following separation

Table 1

Vanadium(V)-catalyzed bromination of aromatic hydrocarbons under two-phase conditions at $25^{\circ} \mathrm{C}$.

\begin{tabular}{|c|c|c|c|c|c|c|c|}
\hline Substrate (mmol) & Catalyst $^{\mathrm{a}}(\mathrm{mmol})$ & Source of bromine (mmol) & $\mathrm{H}_{2} \mathrm{O}_{2}(\mathrm{mmol})$ & Solvent ${ }^{\mathrm{b}}$ & Time (h) & Conversion (\%) & Reference \\
\hline 0.2 & $\mathrm{~V}(\mathrm{~V})(0.2)$ & $\mathrm{KBr}(1.0)$ & 0.4 & $\mathrm{H}_{2} \mathrm{O} / \mathrm{CHCl}_{3}$ & c & 40 & {$[16]$} \\
\hline 0.2 & $\mathrm{~V}(\mathrm{~V})(0.2)$ & $\mathrm{KBr}(1.0)$ & 0.4 & $\mathrm{H}_{2} \mathrm{O} / \mathrm{CHCl}_{3}$ & c & 50 & {$[16]$} \\
\hline 0.2 & $\mathrm{~V}(\mathrm{~V})(0.2)$ & $\mathrm{KBr}(1.0)$ & 0.4 & $\mathrm{H}_{2} \mathrm{O} / \mathrm{CHCl}_{3}$ & c & $>98$ & {$[16]$} \\
\hline 0.4 & $\mathrm{~V}(\mathrm{~V})(0.2)$ & $\operatorname{KBr}(0.5)$ & 0.4 & $\mathrm{H}_{2} \mathrm{O} / \mathrm{CHCl}_{3}{ }^{\mathrm{d}}$ & 4 & 35 & [17] \\
\hline 0.4 & $\mathrm{~V}(\mathrm{~V})(0.2)$ & $\mathrm{KBr}(0.5)$ & 0.4 & $\mathrm{H}_{2} \mathrm{O} / \mathrm{CHCl}_{3}{ }^{\mathrm{d}}$ & 72 & 48 & $\begin{array}{l}{[17]} \\
{[17]}\end{array}$ \\
\hline 0.4 & $\mathrm{Mo}(\mathrm{VI})(0.2)$ & $\mathrm{KBr}(0.5)$ & 0.4 & $\mathrm{H}_{2} \mathrm{O} / \mathrm{CHCl}_{3}{ }^{\mathrm{d}}$ & 4 & 56 & [17] \\
\hline 0.4 & $\operatorname{Mo}(\mathrm{VI})(0.2)$ & $\mathrm{KBr}(0.5)$ & 0.4 & $\mathrm{H}_{2} \mathrm{O} / \mathrm{CHCl}_{3}{ }^{\mathrm{d}}$ & 24 & 68 & [17] \\
\hline
\end{tabular}

a $\mathrm{V}(\mathrm{V})$ as $\mathrm{NH}_{4} \mathrm{VO}_{3}, \mathrm{Mo}(\mathrm{VI})$ as $\left(\mathrm{NH}_{4}\right)_{2} \mathrm{MoO}_{4} \cdot 2 \mathrm{H}_{2} \mathrm{O}$.

b Water adjusted at $\mathrm{pH} 1\left(\mathrm{HClO}_{4}\right)$.

c Time necessary for the complete disappearance of the substrate, 4-24 h depending on the substrate.

d 1000 r.p.m. 
Table 2

Vanadium(V)-catalyzed oxybromination vs. bromination of alkenes under two-phase conditions at $25^{\circ} \mathrm{C}$.

\begin{tabular}{|c|c|c|c|c|c|c|c|c|c|}
\hline \multirow[t]{2}{*}{ Substrate (mmol) } & \multirow[t]{2}{*}{ Catalyst ${ }^{\mathrm{a}}(\mathrm{mmol})$} & \multirow[t]{2}{*}{ Source of bromine (mmol) } & \multirow[t]{2}{*}{$\mathrm{H}_{2} \mathrm{O}_{2}(\mathrm{mmol})$} & \multirow[t]{2}{*}{ Solvent $^{\mathrm{a}}$} & \multirow[t]{2}{*}{ Time $(\mathrm{h})$} & \multirow[t]{2}{*}{ Conversion (\%) } & \multicolumn{2}{|c|}{ Relative ratio } & \multirow[t]{2}{*}{ Reference } \\
\hline & & & & & & & $(\mathrm{OH}, \mathrm{Br})$ & $(\mathrm{Br}, \mathrm{Br})$ & \\
\hline & & & & $\mathrm{OH}$ & & & & & \\
\hline 0.2 & & $\mathrm{BrO}_{3}^{-}, \mathrm{Br}^{-}, \mathrm{H}^{+}$ & & $\mathrm{H}_{2} \mathrm{O} / \mathrm{DCM}$ & $\mathrm{b}$ & 99 & 63 & 37 & [18] \\
\hline 0.2 & & NBS & & $\mathrm{H}_{2} \mathrm{O} / \mathrm{DCM}$ & b & 72 & 10 & 90 & [18] \\
\hline 0.2 & & $\mathrm{HOBr}$ & & $\mathrm{H}_{2} \mathrm{O} / \mathrm{DCM}$ & b & 99 & 25 & 75 & [18] \\
\hline 0.2 & $\mathrm{~V}(\mathrm{~V})(0.2)$ & $\mathrm{KBr}(1.0)$ & 0.2 & $\mathrm{H}_{2} \mathrm{O} / \mathrm{DCM}$ & $\mathrm{b}$ & 79 & 20 & 80 & [18] \\
\hline 0.4 & $\mathrm{~V}(\mathrm{~V})(0.2)$ & $\operatorname{KBr}(0.5)$ & 0.4 & $\mathrm{H}_{2} \mathrm{O} / \mathrm{DCM}$ & 66 & 72 & 94 & 6 & [18] \\
\hline 0.1 & $\mathrm{~V}(\mathrm{~V})(0.2)$ & $\mathrm{KBr}(0.5)$ & 0.1 & $\mathrm{H}_{2} \mathrm{O} / \mathrm{DCM}$ & 24 & 65 & 78 & 22 & [19] \\
\hline 0.2 & $\mathrm{~V}(\mathrm{~V})(0.2)$ & $\mathrm{KBr}(0.5)$ & 0.2 & $\mathrm{bmimBF}_{4}$ & 2 & 27 & 58 & 42 & [19] \\
\hline 0.2 & $\mathrm{~V}(\mathrm{~V})(0.2)$ & $\mathrm{KBr}(0.5)$ & 0.2 & bmimoTf & 2 & 68 & 79 & 21 & [19] \\
\hline 0.2 & $V(V)(0.1)$ & $\operatorname{KBr}(1.0)$ & 0.2 & $\mathrm{H}_{2} \mathrm{O} / \mathrm{bmimPF}_{6}$ & 4 & 96 & 98 & 2 & [19] \\
\hline 0.2 & $\mathrm{~V}(\mathrm{~V})(0.1)$ & $\operatorname{KBr}(1.0)$ & 0.2 & $\mathrm{H}_{2} \mathrm{O} /$ bmimNTf $_{2}$ & 6 & 92 & 97 & 3 & [19] \\
\hline 0.2 & $\mathrm{~V}(\mathrm{~V})(0.1)$ & $\operatorname{KBr}(1.0)$ & 0.2 & $\mathrm{H}_{2} \mathrm{O} / \mathrm{bdmimPF}_{6}$ & 4 & $>99$ & 94 & 6 & [19] \\
\hline 0.2 & $\mathrm{Mo}(\mathrm{VI})(0.2)$ & $\mathrm{KBr}(0.5)$ & 0.4 & $\mathrm{H}_{2} \mathrm{O} / \mathrm{CHCl}_{3}$ & 24 & 97 & 95 & 5 & [17] \\
\hline 0.2 & $\mathrm{Mo}(\mathrm{VI})(0.2)$ & $\operatorname{KBr}(1.0)$ & 0.2 & $\mathrm{H}_{2} \mathrm{O} /$ bmimPF $_{6}$ & 2 & 99 & $>99$ & 1 & [25] \\
\hline 0.2 & $\operatorname{Mo}(\mathrm{VI})(0.2)$ & $\mathrm{KBr}(1.0)$ & 0.2 & $\mathrm{H}_{2} \mathrm{O} /$ bmimNTf $_{2}$ & 2 & 96 & $>99$ & 1 & [25] \\
\hline 02 & $\mathrm{~V}(\mathrm{~V})(0 ?)$ & $\mathrm{KBr}(10)$ & 0.4 & $\mathrm{H}_{2} \mathrm{O} / \mathrm{CH}$ & c & 05 & 0 & 100 & [1, \\
\hline 0.2 & $\mathrm{~V}(\mathrm{~V})(0.1)$ & $\mathrm{KBr}(1.0)$ & 0.2 & $\mathrm{H}_{2} \mathrm{O} / \mathrm{DCM}$ & 6 & 76 & 9 & 91 & [20] \\
\hline 0.2 & $\mathrm{~V}(\mathrm{~V})(0.2)$ & $\operatorname{KBr}(1.0)$ & 0.2 & $\mathrm{H}_{2} \mathrm{O} / \mathrm{bmimPF}_{6}$ & 4 & 74 & 87 & 13 & [20] \\
\hline 0.2 & $\mathrm{~V}(\mathrm{~V})(0.2)$ & $\mathrm{KBr}(1.0)$ & 0.2 & $\mathrm{H}_{2} \mathrm{O} /$ bmimNTf $_{2}$ & 4 & 70 & 87 & 13 & [20] \\
\hline 0.2 & $\mathrm{~V}(\mathrm{~V})(0.2)$ & $\mathrm{KBr}(1.0)$ & 0.4 & $\mathrm{H}_{2} \mathrm{O} / \mathrm{CHCl}_{3}$ & c & 95 & 0 & 100 & [16] \\
\hline 0.2 & $\mathrm{~V}(\mathrm{~V})(0.2)$ & $\mathrm{KBr}(1.0)$ & 0.2 & $\mathrm{H}_{2} \mathrm{O} / \mathrm{DCM}$ & c & 58 & 0 & 100 & [18] \\
\hline 0.2 & $\mathrm{~V}(\mathrm{~V})(0.2)$ & $\operatorname{KBr}(1.0)$ & 0.2 & $\mathrm{H}_{2} \mathrm{O} / \mathrm{DCM}$ & 4 & 64 & 10 & 90 & [20] \\
\hline 0.2 & $\mathrm{~V}(\mathrm{~V})(0.2)$ & $\mathrm{KBr}(1.0)$ & 0.2 & $\mathrm{H}_{2} \mathrm{O} / \mathrm{bmimPF}_{6}$ & 1 & $>99$ & 42 & 58 & [20] \\
\hline 0.2 & $\mathrm{~V}(\mathrm{~V})(0.1)$ & $\operatorname{KBr}(1.0)$ & 0.2 & $\mathrm{H}_{2} \mathrm{O} / \mathrm{bmimNTf}_{2}$ & 1 & 81 & 61 & 39 & [20] \\
\hline
\end{tabular}

${ }^{\text {a }} \mathrm{V}(\mathrm{V})$ as $\mathrm{NH}_{4} \mathrm{VO}_{3}, \mathrm{Mo}(\mathrm{VI})$ as $\left(\mathrm{NH}_{4}\right)_{2} \mathrm{MoO}_{4} \cdot 2 \mathrm{H}_{2} \mathrm{O}$

b Water adjusted at $\mathrm{pH} 1\left(\mathrm{HClO}_{4}\right)$ with $\mathrm{V}$ catalysis.

c 4-24 h depending on the substrate.

of the two-phases and elimination, after drying with $\mathrm{MgSO}_{4}$, of the organic one. On top of this, it has been demonstrated that, upon addition of more $\mathrm{H}_{2} \mathrm{O}_{2}$ and substrate, the reaction continues until complete disappearance of bromide ions.

It is to be said that looking at the system after 15 years, the new requirements of sustainable chemistry are calling for the substitution of the chlorinated phase with a less polluting one or, when possible, to perform the reaction by using the substrate as solvent itself.

A more mechanistic driven study concerning bromination of double bonds [18], clearly indicated that an intermediate was formed in the course of the reaction. To note, the reaction is typically characterized by a good degree of selectivity toward formation of the bromohydrin [12]. In that respect, we observed that the products yields strongly depend on the rate of stirring. In similar experimental conditions other classical brominating systems produce selectively dibromide. There is evidence for substrate coordination, and more nucleophilic substrates favour the formation of bromohydrin. Hammett correlations indicate two parallel processes. On this basis we believe that two intermediates are involved in the process: the first one, a vanadium bound hypobromite ion, responsible for the formation of bromohydrin and the second one, bromine, in charge of the formation of dibromo compounds [8]. Further information of the mechanistic and solution structure studies performed in our system will be discussed more in detail later in the paper. Some of the synthetic results obtained, in particular with styrene and trans-stilbene are reported in Table 2 . In the same table some more recent results obtained after substitution of the chlorinated phase with a hydrophobic ionic liquid are inserted $[19,20]$.

Ionic liquids (ILs), namely compounds entirely formed by ions and liquids at temperature below $100{ }^{\circ} \mathrm{C}$, have been recently proposed as sustainable alternative reaction media in consideration of their peculiar properties, and in particular because their negligible vapour pressure, stability in a wide range of temperature and inertness to moisture and oxygen; in addition they can be tailored for a specific reaction by an accurate selection of a couple of cation and anion [21-23]. Indeed, several reports in the literature indicate that the use of this class of ionic solvents cause in several cases higher reaction rates and better yields and selectivities [24].

In the field of ILs, hydrophilic and hydrophobic labelling [24] is used to identify ILs which either form a single phase with $\mathrm{H}_{2} \mathrm{O}$ or dissolve very small quantity of water, thus forming two-phase systems. 
In particular we considered 1-methyl-3-butylimidazolium, bmim, and 1,2-dimethyl-3-butyl-imidazolium, bdmim, cations with tetrafluoridoborate, $\mathrm{BF}_{4}$, hexafluoridophosphate, $\mathrm{PF}_{6}$, triflate, OTf, and bistrifluoridomethane-sulfonimide, $\mathrm{NTf}_{2}$, anions. Accordingly, the solvents tested in our reactions were: bmimBF$_{4}$, bmi-

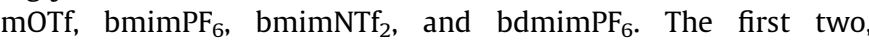
hydrophilic in nature, obviously produced a homogeneous reaction mixture. However, such reactions, carried out with styrene as model substrate (see in Table 2) were disappointing in terms of yield and selectivity even though a shortening of the reaction time was observed. Therefore the homogeneous approach was abandoned.

On the other hand, the data collected in Table 2 related to the use of hydrophobic ILs, clearly indicate that with all the substrates used, the substitution of the chlorinated solvent with an appropriate ionic one results in faster processes and higher selectivity toward the formation of bromohydrins. Very striking is the case of the oxybromination of 1-octene, the less nucleophilic substrate used. In that example, the selectivity $\mathrm{OH}, \mathrm{Br}: \mathrm{Br}, \mathrm{Br}=9: 91$ obtained in DCM is completely reversed both in bmimPF$_{6}$, and bmimNTf reaching a value of 87:13 seldom achievable with other reagents in such mild conditions.

After these interesting results, a similar procedure was examined with phenylethyne, as model alkyne [26]. However, bearing in mind that bromination of a triple bond is expected to be much more difficult than that of a similar alkene, the more reactive $\mathrm{Mo}(\mathrm{VI})$ catalyst was mainly used [26] even though also $\mathrm{V}(\mathrm{V})$ was tested. Being the process not previously reported, oxybromination reaction of phenylethyne was first carried out at room temperature in the $\mathrm{H}_{2} \mathrm{O} / \mathrm{CH}_{2} \mathrm{Cl}_{2}$ system (see Table 3).
As hoped, when the reaction is performed in water/bmimPF $\mathrm{b}_{6}$, it is faster and, even more appealing, the selectivity is definitely shifted toward the dibromoketone. This is a major result, since $\alpha, \alpha$-dibromoacetophenone is a key molecule, with antibacterial, fungicidal and algicidal properties and also it is a valuable intermediate for further transformations, for example, to $\alpha$-haloenolates or biologically active heterocyclic compounds.

To note, an interesting total yield of products of $70 \%$ for vanadium and $88 \%$ for molybdenum catalysis, was obtained by adding hydrogen peroxide portion wise, so that its metal catalyzed decomposition is kept under control.

The mechanistic steps for phenylethyne oxybromination have been proposed [26] in analogy to what found in alkenes oxybromination $[12,19]$ and will be discussed in the next paragraphs.

More recently, the epoxidation of cyclooctene and oxidation of tolyl methyl sulfide were chosen as model reactions for testing the reactivity of some selected vanadium complexes (see Scheme 4 for structures) [27]. Such species contained ligands based on different nitrogen/oxygen functional arms to bind vanadium. Both oxido and dioxido vanadium(V) species, as well as planar and non-planar vanadium settings were considered. Some of these complexes were previously prepared [28] to mimic the reactivity of the active site of vanadium dependent haloperoxidases. For most of the vanadium complexes studied the performance as epoxidation catalysts was not well known, thus, for comparison purposes, epoxidation in acetonitrile was carried out as well.

The epoxidation reaction was not very efficient in MeCN affording at the most $53 \%$ of the epoxide in $24 \mathrm{~h}$ (with complex VO-3). Interestingly, with the first three complexes a faster reaction was

Table 3

Vanadium(V)-catalyzed oxybromination vs. bromination of phenylethyne under two-phase conditions at $25^{\circ} \mathrm{C}$.

\begin{tabular}{|c|c|c|c|c|c|c|c|c|c|c|c|}
\hline \multirow[t]{2}{*}{ Substrate (mmol) } & \multirow[t]{2}{*}{ Catalayst $^{\mathrm{a}}(\mathrm{mmol})$} & \multirow[t]{2}{*}{$\mathrm{KBr}(\mathrm{mmol})$} & \multirow[t]{2}{*}{$\mathrm{H}_{2} \mathrm{O}_{2}(\mathrm{mmol})$} & \multirow[t]{2}{*}{ Solvent $^{\mathrm{b}}$} & \multirow[t]{2}{*}{ Time (h) } & \multirow[t]{2}{*}{ Conversion (\%) } & \multicolumn{4}{|c|}{ Relative ratio } & \multirow[t]{2}{*}{ Reference } \\
\hline & & & & & & & trans $\mathrm{Br}, \mathrm{Br}$ & cis $\mathrm{Br}, \mathrm{Br}$ & $\mathrm{CO}, \mathrm{Br}$ & $\mathrm{CO}, \mathrm{Br}_{2}$ & \\
\hline & & & & & $\mathrm{Br}$ & & & & & & \\
\hline 0.1 & $\mathrm{~V}(\mathrm{~V})(0.1)$ & 0.5 & 0.1 & $\mathrm{H}_{2} \mathrm{O} / \mathrm{DCM}$ & 22 & 30 & 14 & 43 & 4 & 39 & [20] \\
\hline 0.2 & $\mathrm{~V}(\mathrm{~V})(0.2)$ & 1.0 & 0.2 & $\mathrm{H}_{2} \mathrm{O} / \mathrm{bmimPF}_{6}$ & 4 & 22 & 16 & 24 & 16 & 43 & [20] \\
\hline 0.2 & $\mathrm{~V}(\mathrm{~V})(0.2)$ & 1.0 & $0.2^{\mathrm{c}}$ & $\mathrm{H}_{2} \mathrm{O} /$ bmim $\mathrm{PF}_{6}$ & 24 & 70 & 13 & 15 & 9 & 63 & [20] \\
\hline 0.8 & $\mathrm{Mo}(\mathrm{VI})(0.4)$ & 0.5 & 0.8 & $\mathrm{H}_{2} \mathrm{O} / \mathrm{DCM}$ & 18 & 42 & 20 & 56 & 20 & 4 & [26] \\
\hline 0.8 & $\mathrm{Mo}(\mathrm{VI})(0.8)$ & 1.0 & 0.8 & $\mathrm{H}_{2} \mathrm{O} / \mathrm{DCM}$ & 18 & 47 & 11 & 31 & 7 & 51 & [26] \\
\hline 0.8 & $\mathrm{Mo}(\mathrm{VI})(0.8)$ & 1.0 & 0.8 & $\mathrm{H}_{2} \mathrm{O} / \mathrm{CHCl}_{3}$ & 18 & 32 & 11 & 25 & 15 & 49 & [26] \\
\hline 0.2 & $\operatorname{Mo}(\mathrm{VI})(0.1)$ & 1.0 & 0.2 & $\begin{array}{l}\mathrm{H}_{2} \mathrm{O} / \\
\text { bmimNTf }_{2}\end{array}$ & 2 & 32 & 3 & 8 & 43 & 46 & [26] \\
\hline 0.2 & $\mathrm{Mo}(\mathrm{VI})(0.1)$ & 1.0 & $0.2^{c}$ & $\mathrm{H}_{2} \mathrm{O} / \mathrm{bmimPF}_{6}$ & 6 & 88 & 6 & 9 & 10 & 75 & [26] \\
\hline
\end{tabular}
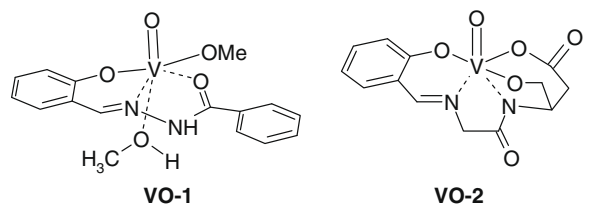

vo-2

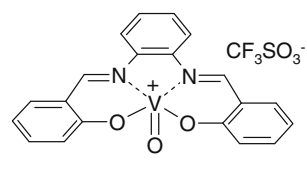

vo-3
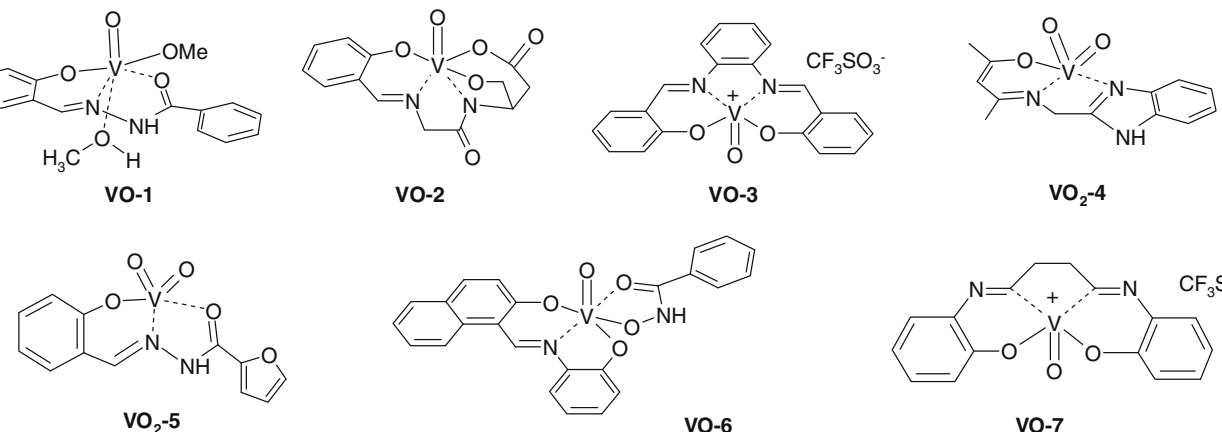

vo-6

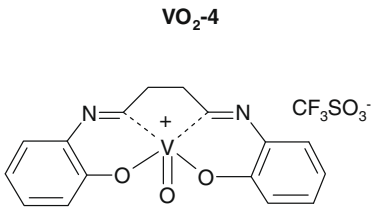

vo-7

Scheme 4. Vanadium Catalysts used in the reactions reported in Table 4 [27]. 
observed in bmimPF ; however, at odd with previous works $[19,26]$, a synthetically interesting improvement of the yields was not observed. In other hydrophobic ILs studied much lower yields of COT epoxide were observed. Furthermore, no COT epoxidation was observed in hydrophilic ionic liquids. Other alkenes (cyclohexene and 1-octene) were much less reactive than COT.

The activity of the vanadium catalysts was also probed towards other hydrocarbons; with adamantane, cyclohexane and benzene no formation of oxidized products was observed. Only traces of phenol were found with VO-6 and large excess of benzene. Such low activity has been attributed to the simultaneous presence of competitive reactions: the oxidation of the substrate and the vanadium catalyzed decomposition of hydrogen peroxide [30]. Thus, with not highly reactive substrates low yields of products are observed. In order to verify this hypothesis oxidation of sulfides was considered. To note, this reaction is interesting both for the preparation of sulfoxides and sulfones [3], as well as for desulfurization of fuels [31].
As expected, with tolyl methyl sulfide, using experimental conditions identical to those used for cyclooctene in bmimPF $_{6}$, the catalysts were very active [27]. However, the reaction time is still quite long (ca. $3 \mathrm{~h}$ ) and sulfone is also formed.

To render this process more appealing, the oxidation was carried out in the presence of microwave activation [32] Considering that the response of ILs to microwave activation is very effective, very low power $(2 \mathrm{~W})$ was applied in order to limit the increase of the temperature in the reaction mixture. The striking results obtained indicate that, in very short reaction times (seconds in comparison with hours) only formation of sulfoxide is observed.

In Table 4 are also mentioned some preliminary, yet disappointing, data obtained in the attempt to extend this approach also to the hydroxylation of benzene. We analyzed already such a reaction [33] after the initial work of Mimoun [34] who published the synthesis and the reactivity of the vanadium peroxido picolinato complex $\mathrm{VO}\left(\mathrm{O}_{2}\right)$ pic, which hydroxylates benzene with

Table 4

Vanadium(V)-catalyzed oxidation reactions at $25^{\circ} \mathrm{C}$.

\begin{tabular}{|c|c|c|c|c|c|c|c|c|}
\hline Substrate (mmol) & Catalyst (mmol) ${ }^{\mathrm{a}}$ & $\mathrm{H}_{2} \mathrm{O}_{2}(\mathrm{mmol})$ & Solvent $^{\mathrm{a}}$ & Time (h) & Yield (\%) & \multicolumn{2}{|c|}{ Relative ratio } & Refere \\
\hline \multicolumn{9}{|c|}{ Epoxidation of cyclooctene } \\
\hline & & & & & & Epoxide & Diol & \\
\hline 0.5 & VO-1 & 0.005 & $\mathrm{MeCN}$ & $24^{\mathrm{b}}$ & 7 & 100 & 0 & [27] \\
\hline 0.5 & VO-2 & 0.005 & $\mathrm{MeCN}$ & $24^{\mathrm{b}}$ & 33 & 100 & 0 & [27] \\
\hline 0.5 & VO-3 & 0.005 & $\mathrm{MeCN}$ & $5^{\mathrm{b}}$ & 53 & 100 & 0 & [27] \\
\hline 0.5 & $\mathrm{VO}_{2}-4$ & 0.005 & $\mathrm{MeCN}$ & $24^{\mathrm{b}}$ & 0 & & & [27] \\
\hline 0.5 & VO-1 & 0.005 & bmimPF$_{6}$ & $5^{\mathrm{b}}$ & 20 & 100 & 0 & [27] \\
\hline 0.5 & Vo-2 & 0.005 & bmimPF $_{6}$ & $4^{\mathrm{b}}$ & 15 & 100 & 0 & [27] \\
\hline 0.5 & $\mathrm{VO}_{2}-3$ & 0.005 & bmimPF $_{6}$ & $4^{\mathrm{b}}$ & 25 & 100 & 0 & [27] \\
\hline 0.5 & Vo-4 & 0.005 & bmimPF $_{6}$ & $5^{\mathrm{b}}$ & 8 & 100 & 0 & [27] \\
\hline
\end{tabular}

Oxidation of tolyl methyl sulfide

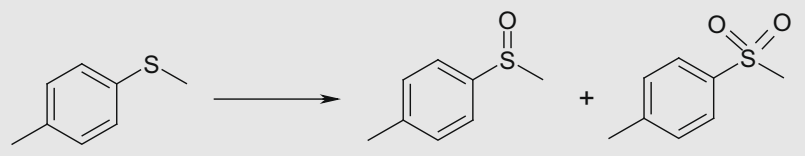

\begin{tabular}{|c|c|c|c|c|c|c|c|c|}
\hline \multirow[b]{2}{*}{0.5} & \multirow[b]{2}{*}{ VO-5 (0.005) } & \multirow[b]{2}{*}{0.5} & \multirow[b]{2}{*}{$\mathrm{bmimPF}_{6}$} & \multirow[b]{2}{*}{$\mathrm{ca} 3^{\mathrm{b}}$} & \multirow[b]{2}{*}{$>99$} & & \multirow[b]{2}{*}{ [27] } \\
\hline & & & & & & 90 & 10 & \\
\hline 0.5 & VO-1 (0.005) & 0.5 & bmimPF $_{6}$ & $\mathrm{ca} 3^{\mathrm{b}}$ & $>99$ & 86 & 4 & [27] \\
\hline 0.5 & VO-6 (0.005) & 0.5 & bmimPF $_{6}$ & ca $3^{\mathrm{b}}$ & $>99$ & 92 & 8 & [27] \\
\hline 0.5 & VO-7 (0.005) & 0.5 & bmimPF $_{6}$ & ca $3^{\mathrm{b}}$ & $>99$ & 83 & 7 & [27] \\
\hline 1.86 & VO-5 (0.0006) & 0.125 & $\mathrm{bmimPF}_{6}$ & $0.009^{c}$ & $>99^{d}$ & 100 & 0 & [27] \\
\hline 1.86 & VO-1 (0.0006) & 0.125 & bmimPF $_{6}$ & $0.012^{c}$ & $>99^{d}$ & 100 & 0 & [27] \\
\hline 1.86 & VO-6 (0.0006) & 0.125 & bmimPF $_{6}$ & $0.013^{c}$ & $97^{\mathrm{d}}$ & 100 & 0 & [27] \\
\hline 1.86 & VO-7 (0.0006) & 0.125 & bmimPF $_{6}$ & $0.012^{c}$ & $>99^{d}$ & 100 & 0 & [27] \\
\hline
\end{tabular}

Hydroxylation of benzene

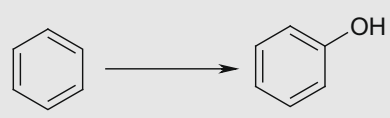

$\begin{array}{llll}\mathrm{VO}\left(\mathrm{O}_{2}\right) \text { pic }(0.048) & 0.48 & \mathrm{MeCN} & 8 \\ \mathrm{VO}\left(\mathrm{O}_{2}\right) \text { pic }(0.048) & 0.048 & \text { bmimBF}_{4} & 24 \\ \mathrm{VO}\left(\mathrm{O}_{2}\right) \text { pic }(0.048) & 0.048 & \text { bmimOTf } & 24 \\ \mathrm{VO}\left(\mathrm{O}_{2}\right) \text { pic }(0.04) & 1.0 & \mathrm{ClCH}_{2} \mathrm{CH}_{2} \mathrm{Cl}_{/} \mathrm{H}_{2} \mathrm{O}^{\mathrm{e}} & 6^{\mathrm{g}} \\ \mathrm{VO}\left(\mathrm{O}_{2}\right) \text { pic }(0.04) & 1.0 & \text { bmimPF }_{6} / \mathrm{H}_{2} \mathrm{O}^{\mathrm{e}} & 8^{\mathrm{g}} \\ \mathrm{VO}\left(\mathrm{O}_{2}\right) \text { pic }(0.04) & 1.0 & \text { bmimNTf }_{2} / \mathrm{H}_{2} \mathrm{O}^{\mathrm{e}} & 8^{\mathrm{g}} \\ \text { bmimVO } & \text { bdmimBF}_{4} & 24 \\ \mathrm{VO}\left(\mathrm{O}_{2}\right) \text { pic }(0.0048)^{\mathrm{f}} & 0.0048 & \text { bdmimBF }_{4} & 24\end{array}$

$\begin{array}{ll}8 & 24 \\ 24 & 0 \\ 24 & 0 \\ 6^{\mathrm{g}} & 4 \\ 8^{\mathrm{g}} & 1 \\ 8^{\mathrm{g}} & 2 \\ 24^{\mathrm{h}} & 5 \\ 24^{\mathrm{h}} & 14\end{array}$

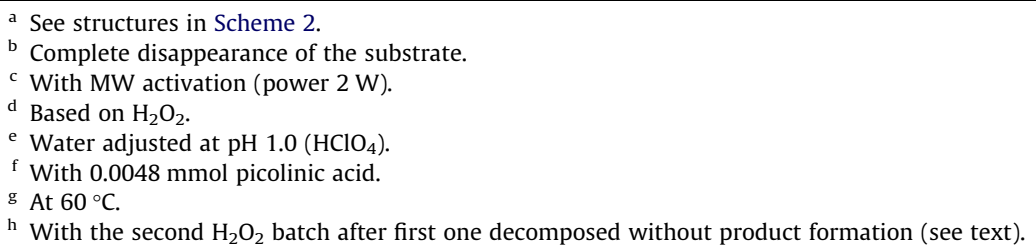


good yields of phenol (up to 70\% in stoichiometric conditions in acetonitrile). Additionally, with an appropriate phase transfer agents, namely 4-(3-heptyl)-pyridine-2-carboxylic acid, we developed a two-phase procedure [29] where benzene and substituted benzenes are hydroxylated to monophenols with fair yields. Considering that inorganic salts as well as organic compounds are generally much more soluble in ILs than in molecular solvents [24], we hoped that hydroxylation of aromatics could take place in a $\mathrm{H}_{2} \mathrm{O} / \mathrm{ILs}$ system, where the aqueous phase contained V-catalyst and picolinic acid, benzene is dissolved in the IL phase and a slow addition of hydrogen peroxide would guarantee a better performance in terms of products formation vs peroxide decomposition.

Unfortunately, very small amounts of phenol were detected

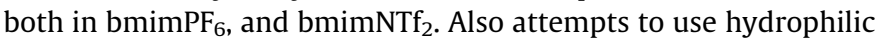
ILs, (bmimBF 4 and bmimOTf) failed. The occurrence of a very different reaction mechanism, i.e. a radical one in the case of benzene hydroxylation, may be the reason why such disappointing results were observed. Trying to verify if this behaviour could be due to low rate of dissolution of the catalyst of in such media, we studied the benzene hydroxylation by forming the catalyst in situ using picolinic acid, hydrogen peroxide and 1-butyl-3methylimidazolium vanadate $\left(\mathrm{bmimVO}_{3}\right)$, a vanadium salt, purposely prepared, likely more soluble in ILs than simple vanadates. Moreover, with the scope to limit interaction with the catalyst, bdmimBF 4 , a less acidic reaction medium, was used. Unexpectedly, after having allowed the decomposition of the initially added peroxide without product formation, some traces of phenol were detected after recharging of the reaction mixture with subsequent portions of $\mathrm{H}_{2} \mathrm{O}_{2}$. This bizarre behaviour may be due to a modification of the nature of the vanadium catalyst in the ionic environment. Therefore, making the effort to understand the peculiar performance in the ionic medium, we have analyzed the spectral (UV-Vis and ${ }^{51} \mathrm{~V}$ NMR) behaviour of vanadium peroxido complexes in ILs [35]. Detail on this aspect are collected in the next paragraph.

\section{Structural studies}

Together with reactivity studies a body of research was dedicated to the elucidation of the solution structures of peroxidovanadates. To this scope a protocol has been suggested [11] which uses a combination of multinuclear NMR, ESI-MS spectroscopy and theoretical calculations. The majority of the experimental work has been carried out in aqueous alcoholic solutions, and in some case also in the presence of appropriate ligands, in order to model some of the natural conditions where vanadium dependent haloperoxidase enzymes (VHPO) work.

In the absence of hydrogen peroxide vanadium (V) is present in aqueous solution as vanadate or vanadate derivatives depending on $\mathrm{pH}$ and reduction potential [4]. The ESI-MS analysis both in positive [10] and negative [36] ion mode, that may be considered as an analogous of acid and basic medium conditions [37], revealed the presence of monomeric and dimeric species, with different coordination spheres. $\mathrm{cis}-\mathrm{VO}_{2}{ }^{+}$is reported to be the major species in aqueous vanadate solutions at $\mathrm{pH} 1$ [4]. In the alcoholic conditions used for detection of positive-ions, where a precise definition of the acidity is not possible species such as $\left[\mathrm{OV}(\mathrm{OX})_{3} \mathrm{H}\right]^{+}$, with $\mathrm{X}=\mathrm{H}$ or $\mathrm{CH}_{3}$, were identified together with dimeric species $\left[\mathrm{OV}-\mathrm{O}-\mathrm{VO}(\mathrm{OH})_{4} \mathrm{H}\right]^{+}$and $\left[\mathrm{OV}-\mathrm{O}-\mathrm{VO}(\mathrm{OCH})_{3}(-\right.$ $\left.\left.\mathrm{H}_{2} \mathrm{O}\right)(\mathrm{OH}) \mathrm{H}\right]^{+}$. ESI-MS findings in anionic mode are in agreement with the knowledge that in neutral and alkaline medium $\mathrm{V}(\mathrm{V})$ exists primarily as monomeric oxyanions $\left(\mathrm{VO}_{4}{ }^{3-}, \mathrm{HVO}_{4}{ }^{2-}\right.$, $\mathrm{H}_{2} \mathrm{VO}_{4}^{-}$) [36].

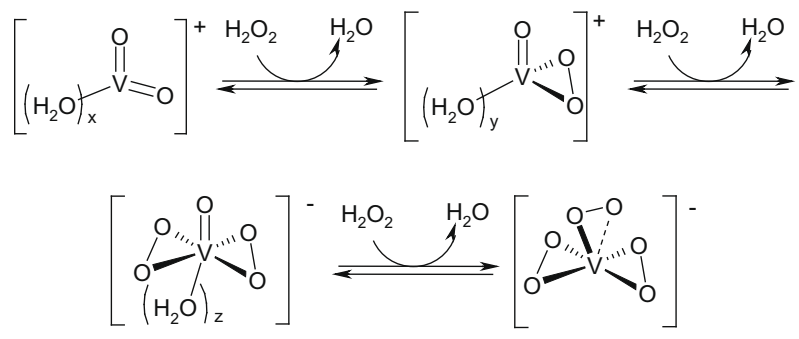

Eq. (1): Peroxidovanadates formation in aqueous media.

The addition of $\mathrm{H}_{2} \mathrm{O}_{2}$ to vanadates solutions produces significant changes in the ESI spectra, as it could have been anticipated knowing the peroxide addition equilibria, which in aqueous solution can be schematically indicated as in Eq. (1) [7].

The positive-ion mode mass spectrum of a methanolic solution containing equimolar amounts of $\mathrm{V}(\mathrm{V})$ and $\mathrm{H}_{2} \mathrm{O}_{2}$, at acid $\mathrm{pH}$ shows peaks corresponding to vanadium monoperoxido compounds $\left[\mathrm{VO}\left(\mathrm{O}_{2}\right)\left(\mathrm{H}_{2} \mathrm{O}\right)_{y}(\mathrm{MeOH})_{w}\right]^{+}$with different coordination sphere composition $(y, w=0-4)[10]$.

Monoperoxido species with one solvent molecule coordinated to the metal center are the most abundant ions observed. When they are isolated within the mass spectrometer and let to react with neutral water or methanol molecules present within the instrument, in low pressure condition, exchange between water and methanol and coordination of a second molecule of solvent are observed [10]. These gas-phase experiments indicate that, in the coordination sphere of monoperoxido vanadium complexes, exchange between water and methanol molecules takes place. Such processes occurs also in solution, as proved by the ${ }^{51} \mathrm{~V}$ NMR spectra line broadening observed when mixed solvents are employed [10]. The plausibility of the exchange process between water and methanol is also supported by ab initio calculations carried out for the addition of $\mathrm{H}_{2} \mathrm{O}$ or $\mathrm{MeOH}$ molecules to the "naked" ion $\left[\mathrm{VO}(\mathrm{O})_{2}\right]^{+}[10]$. The maximum stabilization due to complexation of the aqua ligands is obtained when three molecules are coordinated to vanadium [38]. Further coordination to metal is characterized by a lower hydration energy that can be associated to the formation of the second solvation shell.

As indicated in the previous paragraph, peroxido vanadium complexes are of interest also because they are intermediates in the catalytic cycle of the haloperoxidase enzymes. The accepted mechanism for the enzymatic cycle has been proposed on the basis of two assumptions [4,15]: (i) the oxidation state of the vanadium is $(\mathrm{V})$ and does not change during the catalytic cycle and (ii) the halide does not bind directly to the vanadium atom. Several studies have shown that the important steps in the oxidation of halide ion, to form the halogenating intermediate, are the addition of hydrogen peroxide to $V(V)$ in the prostetic group of the enzyme to produce a peroxido complex and the subsequent protonation of such an intermediate [4]. The rate-determining step of the reaction is the nucleophilic attack of the halide on the peroxido complex generating a " $\mathrm{X}^{+}$equivalent" able to halogenate the organic substrate. A number of intermediates (e.g HOX, $\mathrm{X}_{2}, \mathrm{X}_{3}{ }^{-}, \mathrm{V}_{\mathrm{enz}}-\mathrm{OX}$ ) have been proposed [4]. As well, several groups have proposed various functional models for such enzymes. In particular, we have suggested as functional mimicking the vanadium based two-phase procedure reported in Scheme 3 [16]. Some quite recent studies [12] showed that in our system the vanadium monoperoxido derivative is the species in charge of the formation of the "bromine equivalent" intermediate, the diperoxido species acting just as a reservoir of the actual oxidant. In order to gain direct evidence on the occurrence, composition and structure of the postulated "bromine equivalent" intermediate, the $\mathrm{V} / \mathrm{H}_{2} \mathrm{O}_{2} / \mathrm{H}^{+}$system was 
further investigated by ESI-MS analysis, using a mixed water-alcohol infusion solvent [12]. The addition of $\mathrm{Br}^{-}$produced significant changes to the positive-ion mode mass spectrometric picture discussed previously, consisting of $\left[\mathrm{VO}\left(\mathrm{O}_{2}\right)\left(\mathrm{H}_{2} \mathrm{O}\right)_{y}(\mathrm{MeOH})_{w}\right]^{+}$ions. Formation of new bromine containing $\mathrm{V}(\mathrm{V})$ species is observed, in particular $[\mathrm{VO}(\mathrm{OH})(\mathrm{OBr})]^{+},[\mathrm{VO}(\mathrm{OR})(\mathrm{OBr})]^{+}$and $[\mathrm{VO}(\mathrm{OH})(\mathrm{O}-$ $\left.\mathrm{Br})\left(\mathrm{OH}_{2}\right)\right]^{+}$have been postulated on the basis of isotopic clusters and $\mathrm{MS}^{n}$ spectra. Further support for the formation and stability of such V-containing "bromine equivalent" was obtained with theoretical calculations on the reaction between the monoperoxido derivative and bromine [12]. Interestingly, the most stable species are $[\mathrm{VO}(\mathrm{OH})(\mathrm{OBr})]^{+}$and $\left[\mathrm{VO}(\mathrm{OH})(\mathrm{OBr})\left(\mathrm{OH}_{2}\right)\right]^{+}$.

In alkaline medium and in the absence of hydrogen peroxide, as already indicated, $\mathrm{V}(\mathrm{V})$ exists primarily as monomeric oxyanions in agreement with ESI-MS findings [36]. The negative-ion mode mass spectrum, observed after the addition of equimolar amount of $\mathrm{H}_{2} \mathrm{O}_{2}$ to $\mathrm{V}(\mathrm{V})$, in $\mathrm{H}_{2} \mathrm{O} / 2-\mathrm{PrOH}$ as infusion solvent, consists essentially of two ionic species: i.e. a non peroxidic species $\left[\mathrm{VO}_{2}\left(\mathrm{OPr}^{i}\right)_{2}\right]^{-}$, and a monoperoxido complex $\left[\mathrm{VO}\left(\mathrm{O}_{2}\right)\left(\mathrm{OPr}^{i}\right)_{2}\right]^{-}$. Moreover, $\mathrm{MS}^{2}$ spectra, obtained upon selection of $\left[\mathrm{VO}\left(\mathrm{O}_{2}\right)\left(\mathrm{OPr}^{i}\right)_{2}\right]^{-}$species, consist of a $58 \mathrm{Da}$ fragment expulsion which corresponds to the formal release of $\mathrm{C}_{3} \mathrm{H}_{6} \mathrm{O}$, i.e. an acetone molecule. Monoperoxido vanadium compounds are known to mediate the aerobic oxidation of primary and secondary alcohols to carbonyl derivatives with the parallel reduction of molecular oxygen to $\mathrm{H}_{2} \mathrm{O}_{2}[11,36,39]$. In the specific case 2-PrOH is in fact oxidized to acetone and thus the release of acetone from $\left[\mathrm{VO}\left(\mathrm{O}_{2}\right)\left(\mathrm{OPr}^{i}\right)_{2}\right]^{-}$, observed in gas-phase, may be used as a direct evidence that such oxidation occurs in the coordination sphere of the metal.

Formation of anionic vanadium diperoxido compounds, see Eq. (1), requires higher hydrogen peroxide concentration $\left(\mathrm{H}_{2} \mathrm{O}_{2}: \mathrm{V} \geqslant 3\right)$ and higher $\mathrm{pH}$. When such solutions are analyzed by ESI-MS in negative-ion mode, the majority of the peaks refers to $\mathrm{V}(\mathrm{V})$ diperoxido compounds $\left[\mathrm{VO}\left(\mathrm{O}_{2}\right)_{2}\left(\mathrm{H}_{2} \mathrm{O}\right)_{y}(\mathrm{ROH})_{w}\right]^{-}$containing water and alcohol solvent molecules in the coordination sphere, being the naked ion $\left[\mathrm{VO}\left(\mathrm{O}_{2}\right)_{2}\right]^{-}$the most abundant one [11]. MS ${ }^{2}$ spectra on the latter peak showed decomposition of both peroxido bridges with a 32 Da loss. Ab initio calculations carried out on $\left[\operatorname{VO}\left(\mathrm{O}_{2}\right)_{2}\right]^{-}$ indicate that the peroxide groups are parallel each other and perpendicular to the oxido oxygen and with the vanadium atom raised $0.5 \AA$ out of the plane [7].

Coordination of one or two ligands (L) either solvent or specific molecules like histidine, pyridine etc., to $\left[\mathrm{VO}\left(\mathrm{O}_{2}\right)_{2}\right]^{-}$is a feasible process both in solution and in gas-phase $[6,11,40]$. The stabilization energies obtained by theoretical calculations for the first coordination are in the range $90-133 \mathrm{KJ} / \mathrm{mol}$, depending on $\mathrm{L}$, whereas those associated to the second coordination are lower. Of interest, are the studies carried out by ESIMS on the coordination of histidine and histidine-like ligands to diperoxido derivative. The choice of these molecules is suggested by the fact that haloperoxidases enzymes contain histidine residues coordinated to vanadium [41]. Coordination of one or two ligands to the metal center has been observed and the related $\left[\mathrm{VO}\left(\mathrm{O}_{2}\right)_{2} \mathrm{~L}\right]^{-}$and $\left[\mathrm{VO}\left(\mathrm{O}_{2}\right)_{2} \mathrm{~L}_{2}\right]^{-}$species have been fully characterized. In particular, with $\mathrm{MS}^{2}$ experiments, specific fragmentations of the peroxidic moiety were distinguished as a function of the nature and the number of the ligands. Diperoxido compounds containing one heteroligand in the coordination sphere release a $32 \mathrm{Da}$ fragment via decomposition of both peroxidic bridges, whereas in the presence of two ligands the expulsion of a $34 \mathrm{Da}$ fragment (i.e. formally a molecule of $\mathrm{H}_{2} \mathrm{O}_{2}$ ) is observed when a carboxylic function is present in the framework of the ligand itself. This latter peculiar fragmentation appears to be an evidence on the occurrence of the protonation of the peroxido oxygens as a crucial step in the activation of vanadium peroxido compounds [11]; a step with biochemical implication in the reactivity of vanadium haloperoxidases enzymes. Indeed by using ${ }^{17} \mathrm{O}$-NMR and enriched ${ }^{17} \mathrm{O}-\mathrm{H}_{2} \mathrm{O}_{2}$, signals likely due to a hydroperoxidic form of Ascophillum nodosum bromoperoxidase enzyme have been detected [42].

Further addition of $\mathrm{H}_{2} \mathrm{O}_{2}$ ( $\geqslant 50$ equivalents) transform the diperoxido species into the triperoxido derivative, see last equilibrium of Eq. (1). By ESI-MS analysis, the occurrence of the species $\left[\mathrm{V}\left(\mathrm{O}_{2}\right)_{3}\right]^{-}$as base peak is observed for $\mathrm{H}_{2} \mathrm{O}_{2}$ excesses higher than 200 equivalents [43]. Interestingly if the triperoxido derivative is selected and submitted to collision induced decomposition $\left(\mathrm{MS}^{n}\right)$, subsequent fragmentation of two of the three peroxidic bridges is observed affording the diperoxido complex $\left[\mathrm{VO}\left(\mathrm{O}_{2}\right)_{2}\right]^{-}$and the unprecedented reported dioxido monoperoxido species $\left[\mathrm{VO}_{2}\left(\mathrm{O}_{2}\right)\right]^{-}[7]$.

Theoretical calculations have been also carried out aimed to obtain the optimized structures of the vanadium triperoxido complex and of the dioxido monoperoxido species [7]. Moreover other calculations were performed to analyze the formation of all the peroxidic species resulting from a sequence of addition of $\mathrm{H}_{2} \mathrm{O}_{2}$, release of $\mathrm{H}_{2} \mathrm{O}$ and proton transfer equilibria. Such calculations showed that the formation of mono and diperoxido species is favourable processes while the further reaction of protonated diperoxido vanadates with hydrogen peroxide yielding the triperoxido complex is endothermic [7].

Linking these theoretical results to the reactivity, we studied the oxidation of cyclobutanone to 4-hydroxybutanoic acid with the above cited triperoxido vanadium compound, in alcohol/water mixtures, and observed that it does not act as nucleophilic oxidant, but only as source of $\mathrm{HOO}^{-}$anion [43]. Our results indeed demonstrated that the claims on nucleophilic oxidant character of triperoxido vanadates is doubtless incorrect [44].

In connection with our reactivity studies in ILs, and in the frame of an European collaboration, ${ }^{51} \mathrm{~V}$ NMR experiments have been performed with the aim to elucidate the nature of vanadates and peroxidovanadates in hydrophilic ionic liquids (i.e. bmimBF 4 , bmimTfO and bdmimBF 4 ) [35]. Preliminary UV-Vis analysis of diperoxidovanadate revealed a very strong absorbance enhancement changing the solvent from water to hydrophilic ionic liquid. To better understand this behaviour similar experiments, analyzing different solution of vanadates and peroxidovanadates from water up to water/90\% IL, were accomplished with ${ }^{51} \mathrm{~V}$ NMR. The general outcome was the shifting and the broadening of the diperoxidovanadate peak. Moreover a peak, with a chemical shift not previously reported, appeared. The relative intensity of this peak became higher increasing the amount of the IL in the solution and this behaviour is more pronounced with tetrafluoridoborate anion, as in the case of UV-Vis spectra.

Without entering too much in the detail of the work, the principal result obtained is involvement of $\mathrm{BF}_{4}{ }^{-}$anion in the formation of the three typical peaks observed for vanadates solutions in tetrafluoridoborate based ionic liquids (at $-465,-548$ and $-612 \mathrm{ppm}$ ). This behaviour is probably due to the fact that it acts as a fluorinating agent [45] in presence of a suitable acceptor, such as vanadium [46]. Moreover, it is well known [35] that aqueous sodium tetrafluoridoborate solutions are acid since hydrolysis occurs producing $\mathrm{HF}$, therefore the appearance of decavanadate peaks is expected. On the other hand, it can directly interact with vanadates producing fluorido containing vanadium species.

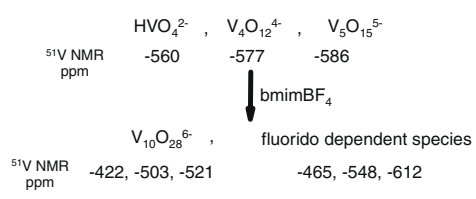

Eq. (2): Vanadates in bmimBF$_{4}$ as detected by ${ }^{51} \mathrm{~V}$ NMR. 
Ionic liquids containing a more stable anion than tetrafluoridoborate (viz. triflate), have no particular effect on the spectrum of aqueous vanadate solutions, except for peak broadening.

On the other hand, ionic liquids seem to have an effect on peroxidovanadate species, independently of the anion. In fact, while in water the addition of $\mathrm{H}_{2} \mathrm{O}_{2}$ produces only one peak, i.e. the diperoxido complex, in ionic liquids other peaks are present. Taking into account the fluorinating ability of tetrafluoridoborate, the most intense among the secondary peaks that form in the presence of $\mathrm{BF}_{4}{ }^{-}$may be seen as diperoxido fluoro vanadate $\left[\mathrm{VO}\left(\mathrm{O}_{2}\right)_{2} \mathrm{~F}\right]^{2-}$ [47], since it appears as a doublet and at lower ppm values than other diperoxidovanadate species. Time sequence spectra seem to suggest that this fluorido species is in equilibrium with diperoxidovanadate.

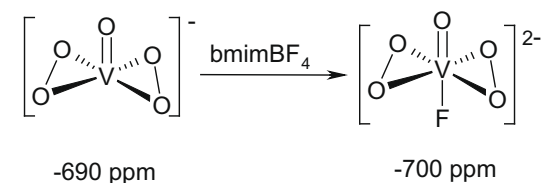

Eq. (3): Di-peroxidovanadates in bmimBF 4 as detected by ${ }^{51} \mathrm{~V}$ NMR [35].

Concerning the peroxido peaks appearing in ionic liquids other than bmimBF 4 (viz. triflate), different anion interactions can be considered, i.e. coordination, or dimerization of peroxidovanadate species, in analogy with what has been observed in acetonitrile [48]. The formation and the low stability of these secondary species may be the reason for the enhanced peroxide consumption rate.

The analyses performed on the $\mathrm{V} / \mathrm{H}_{2} \mathrm{O}_{2} /$ picolinic acid system, prove that, in the conditions adopted to carry out benzene hydroxylation, $\operatorname{VO}\left(\mathrm{O}_{2}\right) \mathrm{Pic}\left(\mathrm{H}_{2} \mathrm{O}\right)_{2}$ forms, as indicated by the peaks around $-600 \mathrm{ppm}[49,50]$. The addition of further hydrogen peroxide only seems to increase the amount of diperoxidovanadate. At odd with other peroxido species, the monoperoxido-picolinate absorption is not shifted by the addition of ionic liquid. This behaviour is in contrast to that in acetonitrile [51]. Indeed $\mathrm{VO}\left(\mathrm{O}_{2}\right) \mathrm{Pic}\left(\mathrm{H}_{2} \mathrm{O}\right)_{2}$ in acetonitrile reacts with benzene, while under similar conditions in bdmimBF$_{4}$ only a small amount of phenol is formed (see Table 4) [25].

\section{Mechanistic studies}

From the mechanistic point of view, one of our initial major efforts has been the elucidation of the very complex reaction pathway, involving radical chain steps, of the direct benzene hydroxylation carried out in non coordinating solvents by picolinate $\mathrm{V}(\mathrm{V})$ monoperoxido complexes $[3,34]$. This species, quite stable in protic solvents, rapidly decomposes in $\mathrm{CH}_{3} \mathrm{CN}$, with evolution of molecular oxygen and formation of a yellow insoluble dimeric complex. When the peroxidic complex is allowed to decompose in the presence of benzene, phenol is formed in fair yields at room temperature. The authors proposed that phenol was directly formed by a radical species generated in the homolitic cleavage of one metal-peroxido oxygen bond [34].

On the other hand, we have demonstrated, investigating the reactivity of picolinate peroxido complex in various solvents and in presence of both one-electron donors and radical traps, that the active oxidizing species is a vanadium complex resulting from the monoreduction of the picolinate monoperoxido complex, formally a radical-anion derivative. Such initiation process readily occurs in non coordinating solvents whereas it is almost suppressed in $\mathrm{CH}_{3} \mathrm{OH}$, water or DMF. Assuming that the radical-anion derivative is the chain carrier, we proposed a rather complex reaction mechanism (see Scheme 5) which accounted for all the observed competitive reactions: peroxido complex decomposition, benzene hydroxylation and dioxygen formation.

In that quite long story, the identification of competent intermediates has been complicated and therefore the reaching of the results was highly rewarding. The work is indeed quite old, however the results obtained are still of interest considering the importance of the direct hydroxylation of aromatic rings, therefore here we show the mechanistic details (Scheme 5 ) while we refer interested readers to the original papers which report the whole studies both mechanistic and synthetically oriented [29,30,33,52]. More recently, the attention was devoted to the comprehension of the mechanistic details of the oxybromination reactions in the twophase system, indeed by combining reactivity analysis with spectroscopic techniques, mainly ${ }^{51} \mathrm{~V}$ NMR [6], we have been able to identify monoperoxido vanadium complexes as the competent oxidant of bromide ion, while the diperoxido vanadium species likely acts as a reservoir of the active oxidant. When alkenes are the substrates, two products are usually observed: bromohydrin and dibromide [12]. Interestingly, the reaction is typically characterized by a good degree of selectivity toward formation of the bromohydrin while in similar conditions, other classical brominating reagents produce selectively dibromide. Moreover, we observed the dependence of products yields on the rate of stirring, and evidence has been obtained for substrate coordination, as indicated by the preferential formation of bromohydrin from more nucleophilic substrates. Interestingly, Hammett correlations indicate two parallel processes, therefore our mechanistic proposal includes two intermediates: i.e. a vanadium bound hypobromite ion, responsible for the formation of bromohydrin and the second one, bromine, in charge of the formation of dibromo compounds (see Scheme 6) [7,12].

Accordingly, the hypobromite-like species should be directly involved in the " $\mathrm{Br}^{+}$" transfer process or, at least, it is one of the active species in the bromination process [53]. The occurrence, during the catalytic cycle, of a similar species where the equatorial peroxido oxygen is protonated and the $\mathrm{Br}^{-}$is prone to coordinate the other peroxidic oxygen has been recently proposed [54].

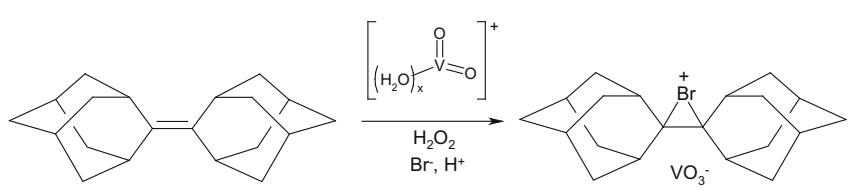

Eq. (4): Adamantylideneadamantane bromination in two-phase conditions [55].

As additional support to the involvement of a $\mathrm{V}(\mathrm{V})$ containing brominating species, we found that in the two-phase oxybromination reaction with adamantylideneadamantane, a molecule containing an hindered double bond whose reactivity in standard bromination ends at the stage of bromiranium ion, salts of such cation have been isolated and fully characterized (Eq. (4)) [55].

On the basis of the experimental data discussed in the previous paragraph and also with the aid of ab initio calculations and spectrometric data, a mechanistic scheme has been proposed where bromohydrin and dibromoderivative are obtained through two parallel pathways, both starting from the hypobromite-like vanadium intermediate, generated by the reaction between monoperoxido vanadium and bromide ion (see Scheme 7).

Such species can react with another bromide ion to give $\mathrm{Br}_{2}$ that brominates the double bond; otherwise it can react with substrate, forming a bromiranium intermediate that reacting with a water molecule belonging to the metal coordination sphere, forms the bromohydrin. 

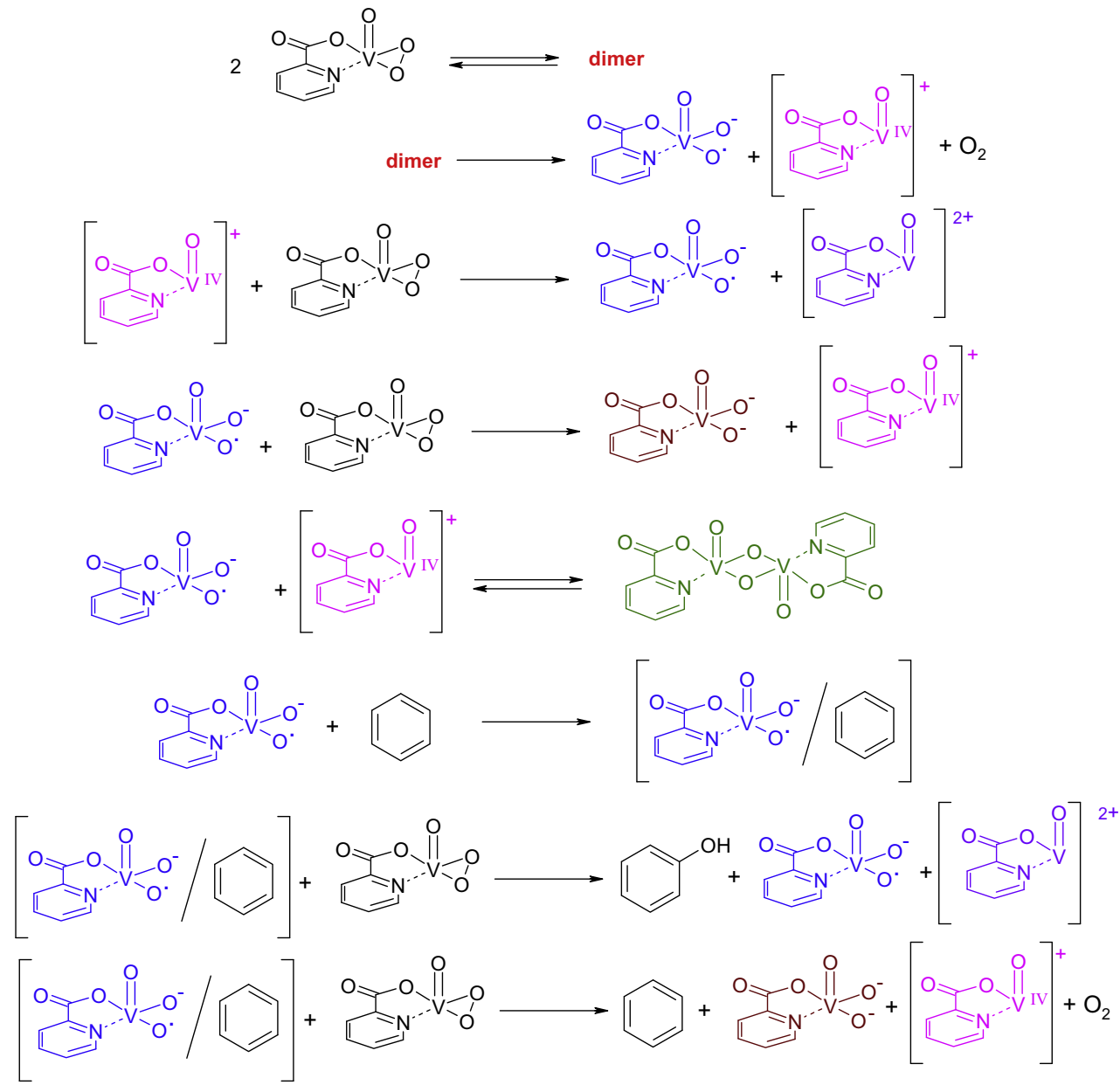

Scheme 5. Reaction mechanism scheme for benzene hydroxylation with picolinate $V(V)$ monoperoxido complex.

To render such procedure even more sustainable, the chlorinated organic solvents have been replaced with ionic liquids. When the model reactions have been carried out in hydrophobic ionic liquids, better yields and better selectivity towards bromohydrin were observed. In addition lower amounts of catalyst, without significant loss in the efficiency, could be used.

Therefore, provided that our proposed reaction mechanism still holds in ILs [25], these improvements can be ascribed to the ionic environment which likely from one side disfavours the transfer of bromine (in charge of the formation of dibromoderivate) in the phase where the substrate is dissolved; while, it allows a better phase transfer of the vanadium containing catalytic active species from water. Furthermore, the selectivity data strongly support the idea that in the ionic environment a higher concentration of the active species in the IL phase, and a slower escape from the organized solvent cage, assist the reaction between the bromiranium intermediate and a water molecule bound to vanadium. The obvious result is a more selective and faster formation of bromohydrins. In this respect the data obtained in the reaction with trans-stilbene in molecular solvent, where formation of both stereoisomers of the halohydrin was observed, suggest that in such media the more stable carbocation is formed, while formation of bromiranium ion is favoured ILs.

In analogy with the mechanism indicated in Scheme 7, also the pathways for oxybromination of triple bonds have been sketched (Scheme 8) [19,25,26].

This mechanistic scheme well explains the experimental results, in particular also those obtained by using hydrophobic ILs. In fact, the disfavoured formation of 1,2-dibromostyrene on going from dichloromethane to $\mathrm{bmimPF}_{6}$ can be ascribed to an inhibited formation of molecular bromine in the latter medium, where the functionalization of the substrate is likely to occur. Moreover, the internal structure of IL may help in keeping the reactive species within the organized solvent cage, thus rendering the reaction faster.

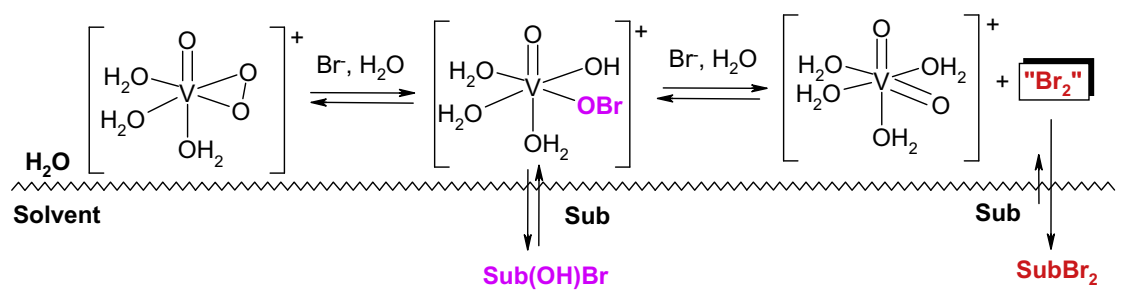

Scheme 6. Competent intermediates involved in the vanadium catalyzed oxybromination reaction in two-phase conditions. 


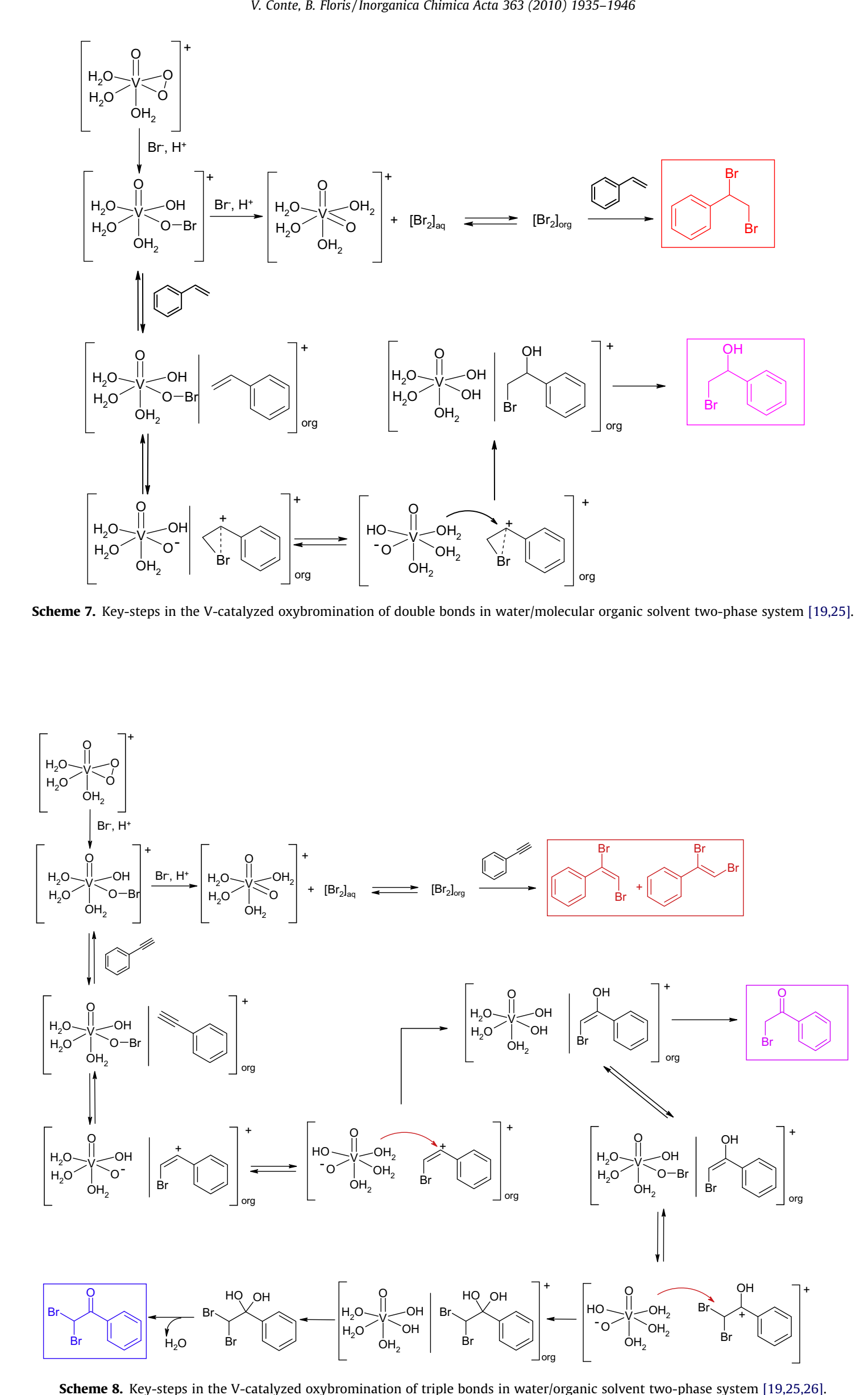




\section{Conclusions}

In this short account of our work in the field of vanadium catalyzed oxidation reactions we intended to demonstrate the close interconnection existing between reactivity, structural and mechanistic studies when applied to catalysis. We also hope that this work will stimulate more readers to enter and possibly explore the wide range of application of vanadium in chemistry, which is absolutely not restricted to our small research field but it spans [2,4] from organic synthesis, biochemical processes, medicinal chemistry, to inorganic chemistry, materials and so on.

\section{Acknowledgements}

We would like to recognize all the dedicated work of our collaborators, students and colleagues without their contributions no papers to cite would exist. All the names are present in the references and we warmly thank all of them. A special mention goes to the enthusiasm, the competence and the friendship of Prof. Olga Bortolini, Università della Calabria e prof. Marcella Bonchio ITM-CNR sezione di Padova, Università di Padova.

EU COST actions D12, D29 and D40 were also essential for creating a very stimulating international framework of collaborating laboratories in different European countries.

\section{References}

[1] (a) D. Rehder, Org. Biomol. Chem. 6 (2008) 957. and references cited therein; b) D. Rehder, Bioinorganic Vanadium Chemistry, Wiley, Chichester, 2008.

[2] (a) A. Butler, A.H. Baldwin, Structure and Bonding - Metal Sites in Proteins and Models, vol. 89, Springer-Verlag, Berlin-Heidelberg, Dordrecht, 1997. and references cited therein;

(b) V. Pecoraro, C. Slebodnick, B. Hamstra, in: D.C. Crans, A. Tracey (Eds.) Vanadium Compounds: Chemistry Biochemistry and Therapeutic Applications, ACS Symposium Series 711, 1998, (Chapter 12).

[3] V. Conte, O. Bortolini, in: Z. Rappoport (Ed.), The Chemistry of Peroxides Transition Metal Peroxides. Synthesis and Role in Oxidation Reactions, Wiley Interscience, 2006. and references cited therein.

[4] D.C. Crans, J.J. Smee, E. Gaidamauskas, L. Yang, Chem. Rev. 104 (2004) 849. and references cited therein.

[5] K.H. Thompson, J.H. McNeill, C. Orvig, Chem. Rev. 99 (1999) 2561.

[6] O. Bortolini, M. Carraro, V. Conte, S. Moro, J. Inorg. Biochem. 80 (2000) 41.

[7] O. Bortolini, V. Conte, J. Inorg. Biochem. 99 (2005) 1549. and references cited therein.

[8] O. Bortolini, V. Conte, Mass Spectrom. Rev. 25 (2006) 724

[9] V. Conte, F. Di Furia, S. Moro, in: D.C. Crans, A. Tracey (Eds.), ACS Series Book 711: Vanadium Compounds: Chemistry, Biochemistry and Therapeutic Applications, 1998, p. 136.

[10] O. Bortolini, V. Conte, F. Di Furia, S. Moro, Eur. J. Inorg. Chem. (1998) 1193.

[11] O. Bortolini, M. Carraro, V. Conte, S. Moro, Eur. J. Inorg. Chem. (1999) 1489

[12] O. Bortolini, M. Carraro, V. Conte, S. Moro, Eur. J. Inorg. Chem. (2003) 42.

[13] P.T. Anastas, J.C. Warner, Green Chemistry: Theory and Practice, Oxford University Press, New York, 1998.
[14] See as an example: G.J. Colpas, B.J. Hamstra, J.W. Kampf, V.L. Pecoraro, J. Am. Chem. Soc. 118 (1996) 3469.

[15] A. Butler, Coord. Chem. Rev. 187 (1999) 17.

[16] V. Conte, F. Di Furia, S. Moro, Tetrahedron Lett. 35 (1994) 7429.

[17] V. Conte, F. Di Furia, S. Moro, Tetrahedron Lett. 37 (1996) 8609.

18] M. Andersson, V. Conte, F. Di Furia, S. Moro, Tetrahedron Lett. 36 (1995) 2675

[19] V. Conte, B. Floris, P. Galloni, A. Silvagni, Pure Appl. Chem. 77 (2005) 1575.

[20] V. Conte, B. Floris, A. Silvagni, in: K. Kustin, J. Costa Pessoa, D.C. Crans (Eds.), ACS Symposium Series 974: Vanadium: The Versatile Metal, 2007, p. 28.

[21] T. Welton, Chem. Rev. 99 (1999) 2071.

[22] P. Wasserscheid, W. Keim, Angew. Chem., Int. Ed. 39 (2000) 3772.

[23] R.A. Sheldon, Chem. Commun. (2001) 2399.

[24] P. Wasserscheid, T. Welton, Ionic Liquids in Synthesis, 2nd ed., Wiley-VCH, Weinheim, 2008.

[25] A. Silvagni, PhD tesi, University of Roma Tor Vergata, 2007.

[26] V. Conte, B. Floris, P. Galloni, A. Silvagni, Adv. Synth. Catal. 347 (2005) 1341.

[27] V. Conte, F. Fabbianesi, B. Floris, P. Galloni, D. Sordi, I.W.C.E. Arends, M. Bonchio, D. Rehder, D. Bogdal, Pure Appl. Chem. 81 (2009) 1265.

[28] (a) M.R. Maurya, S. Agarwal, C. Bader, M. Ebel, D. Rehder, Dalton Trans. (2005) 537 ; (b) M.R. Maurya, A. Kumar, M. Ebel, D. Rehder, Inorg. Chem. 45 (2006) 5924.

[29] M. Bianchi, M. Bonchio, V. Conte, F. Coppa, F. Di Furia, G. Modena, S. Moro, S Standen, J. Mol. Catal. 83 (1993) 107.

[30] M. Bonchio, V. Conte, F. Di Furia, G. Modena, S. Moro, J.O. Edwards, Inorg. Chem. 33 (1994) 631

[31] C. Song, Today 86 (2003) 211.

[32] S. Berardi, M. Bonchio, M. Carraro, V. Conte, A. Sartorel, G. Scorrano, J. Org Chem. 72 (2007) 8954.

[33] M. Bonchio, V. Conte, F. Di Furia, G. Modena, S. Moro, J. Org. Chem. 59 (1994) 6262.

[34] H. Mimoun, L. Saussine, E. Daire, M. Postel, J. Fisher, R. Weiss, J. Am. Chem. Soc 105 (1983) 3101

[35] I. Bányai, V. Conte, L. Pettersson, A. Silvagni, Eur. J. Inorg. Chem. (2008) 5373.

[36] M. Bonchio, O. Bortolini, V. Conte, S. Primon, J. Chem. Soc., Perkin Trans. 2 (2001) 763.

[37] G. Wang, R.B. Cole, in: R.B. Cole (Ed.), Electrospray Ionization Mass Spectrometry: Fundamentals, Instrumentation and Applications, Wiley, 1997. Chapter 4.

[38] A. Bagno, V. Conte, F. Di Furia, S. Moro, J. Phys. Chem. A 101 (1997) 4637.

[39] V. Conte, F. Di Furia, G. Modena, J. Org. Chem. 53 (1988) 1665.

[40] I. Andersson, S. Angus-Dunne, O. Howarth, L. Pettersson, J. Inorg. Biochem. 80 (2000) 51.

[41] A. Messerschmidt, L. Prade, R. Wever, Biol. Chem. 378 (1997) 309.

[42] M. Căsny, D. Rehder, H. Schmidt, H. Vilter, V. Conte, J. Inorg. Biochem. 80 (2000) 157.

[43] M. Bonchio, O. Bortolini, V. Conte, S. Moro, Eur. J. Inorg. Chem. (2001) 2913.

[44] (a) M.N. Bhattachrjee, M.K. Chaudhuri, N.S. Islam, Inorg. Chem. 28 (1989) 2420 ;

(b) M.N. Bhattachrjee, S.K. Chettri, M.K. Chaudhuri, N.S. Islam, S.R. Barman, J. Mol. Catal. 78 (1993) 143.

[45] E.A. Lawton, A. Levy, J. Am. Chem. Soc. 77 (1955) 6083.

[46] M.C. Chakravorti, A.R. Sarkar, J. Fluorine Chem. 8 (1976) 255

[47] J. Chrappová, P. Schwendt, J. Marek, J. Fluorine Chem. 126 (2005) 1297.

[48] C. Slebodnick, V.L. Pecoraro, Inorg. Chim. Acta 283 (1998) 37.

[49] I. Andersson, A. Gorzsás, L. Pettersson, Dalton Trans. (2004) 421.

[50] V. Conte, F. Di Furia, S. Moro, J. Mol. Catal. (1994) 323.

[51] V. Conte, F. Di Furia, S. Moro, Inorg. Chim. Acta 272 (1998) 62.

[52] M. Bonchio, V. Conte, F. Di Furia, G. Modena, J. Org. Chem. 54 (1989) 4368.

[53] M.J. Clague, N.L. Keder, A. Butler, Inorg. Chem. 32 (1993) 4754.

[54] G. Zampilla, P. Fantucci, V.L. Pecoraro, L. De Gioia, J. Am. Chem. Soc. 127 (2005) 953.

[55] O. Bortolini, C. Chiappe, V. Conte, M. Carraro, Eur. J. Org. Chem. (1999) 3237. 